\title{
Performance Analysis of Nail Walls in Jointed Rocks Based on Excavation-Induced Damage
}

\author{
"Naeimifar I.; Department of Civil Engineering, Hashtgerd \\ Branch, Islamic Azad University, Hashtgerd, Iran \\ Yasrobi Sh., Uromeie A., Hashemi H.; \\ Tarbiat Modares University, Tehran, Iran \\ Received: 3 Sep 2014 \\ Revised 10 Nov 2014
}

\begin{abstract}
Evaluation of the excavation-induced ground movements is an important design aspect of supporting system in urban areas. This evaluation process is more critical to the old buildings or sensitive structures exist in the excavation-affected zone. Frame distortion and crack generation are predictor of building damage resulted from excavation-induced ground movements, which pose challenges to projects involving deep excavations. Geological and geotechnical conditions of excavation area have significant effects on excavationinduced ground movements. In some cases, excavation area may be located in the jointed or weathered rocks. Under such conditions, the geological properties of supported ground becomes more noticed due to the discontinuities and anisotropic effects. This paper is aimed to study the performance of excavation walls supported by nails in jointed rocks medium. The performance of nailed wall is investigated based on evaluating the excavation-induced ground movements and
\end{abstract}

*Corresponding author i.naeimifar@yahoo.com 
damage levels of structures in the excavation-affected zone. For this purpose, a set of calibrated 2D finite element models are developed by taking into account the nail-rock-structure interactions, the anisotropic properties of jointed rock, and the staged construction process using ABAQUS software. The results of this paper highlight effects of different parameters such as joint inclinations, anisotropy of rocks and nail inclinations on deformation parameters of excavation wall supported by nails, and induced damage in the structures adjacent to the excavation area. The results show that the relationship between excavation-induced deformation and the level of damage in the adjacent structure.

Keywords: Excavation, Nailed Wall, Performance, Damage, Jointed Rock.

\section{Introduction}

In recent years, a significant rise has been reported in use of soil nail walls as a cost-beneficial alternative to conventional retaining walls executed in top-to-bottom excavations. The construction procedure of soil nail walls is well-described in the literature [1]. The process involves installation of the closely spaced steel bars (i.e., nails) in pre-drilled holes, which are subsequently encased in grout. Similarly, nailing method is used to stabilize the excavation wall in jointed or weathered rocks medium. This stabilization process is known as "Rock Nail Wall" [2]. According to literature, rock nailing refers to a procedure of installing reinforcing elements into a rock mass exposed by an excavation in order to form an internally supported structure. Similar to soil nail wall, in rock nailing 
construction reinforcing elements are installed in a systematic array as the excavation progresses: Each row of elements is installed into natural material before the next increment of excavation [2].

Under both medium conditions, steel bars act as passive elements in response to the deformation of the reinforced ground during subsequent excavation activities [3]. The supported ground should be active to develop tensile and shear capacity in steel bars. In other word, movement must occur in supported ground for creating tensile and shear stress in steel bars. This movement is a potential source for excavation-induced building damage and leads to legal disputes in urban area.Soil/Rock nail wall deflections and resultant building damage highly depends on the performance of nail in the supported medium. Thus, to evaluate the soil/rock nail wall performance, wall deflections and damage of structure in the Excavation-Affected Zone (EAZ) should be investigated.

Most research efforts have been focused on the performance of soil nail wall while performance of rock nail wall (RNW) has received less attention, despite the fact that in some projects excavation area may be located in the jointed or weathered rock medium. Performance assessment of RNW seems to be a central and yet difficult issue to be addressed by researchers. Considering the similarity between RNW and soil nail wall in terms of construction sequence, applications, load transfer mechanisms, and deformability response, the concept of soil nail wall performance can be extended to RNW performance. 
Performance study of soil nail wall has been a long-standing issue in geotechnical engineering. Over the past decades, significant studies have been conducted to assess the performance of soil nail wall in the framework of experimental and numerical methods.

In stabilizing the excavation wall by nailing method, ExcavationInduced Ground Movements (EIGM) and resulted excavation wall deformation and ground settlement are unavoidable. In soft soil, the value of maximum horizontal deformations of wall face can increase up to $0.5 \%$ of the wall height [4]. For weathered rock, stiff soil, sandy soil and fine-grained soil, the value of horizontal deformation can be estimated as follow [1]:

$$
\delta_{\mathrm{h}}=\left(\frac{\delta_{\mathrm{h}}}{\mathrm{H}}\right)_{\mathrm{i}} \times \mathrm{H}
$$

where, $\left(\frac{\delta_{\mathrm{h}}}{\mathrm{H}}\right)_{\mathrm{i}}$ is a ratio dependent on soil/rock conditions presented in table 1 and $\mathrm{H}$ is wall height.

Table 1.Values of $\delta_{h} / H$ as a function of soil ground conditiond

\begin{tabular}{cccc}
\hline Variable & $\begin{array}{c}\text { Weathered } \\
\text { Rock } \\
\text { and Stiff Soil }\end{array}$ & $\begin{array}{c}\text { Sandy } \\
\text { Soil }\end{array}$ & $\begin{array}{c}\text { Fine- } \\
\text { Grained } \\
\text { Soil }\end{array}$ \\
\hline$\delta_{\mathrm{h}} / \mathrm{H}$ & $1 / 1000$ & $1 / 500$ & $1 / 333$ \\
\hline
\end{tabular}

Other estimation of horizontal deformation is presented in Figure1. As shown in this Figureure, the maximum predicted value of horizontal deformation can increase up to $0.5 \%$ of the wall height.

Horizontal deformation of excavation wall can also be predicted based on flexibility ratio of wall as shown in Figure 2 [5, and 6]. In the Figureure, the horizontal ax is flexibility ratio of wall and is defined by Eq. 2 . 


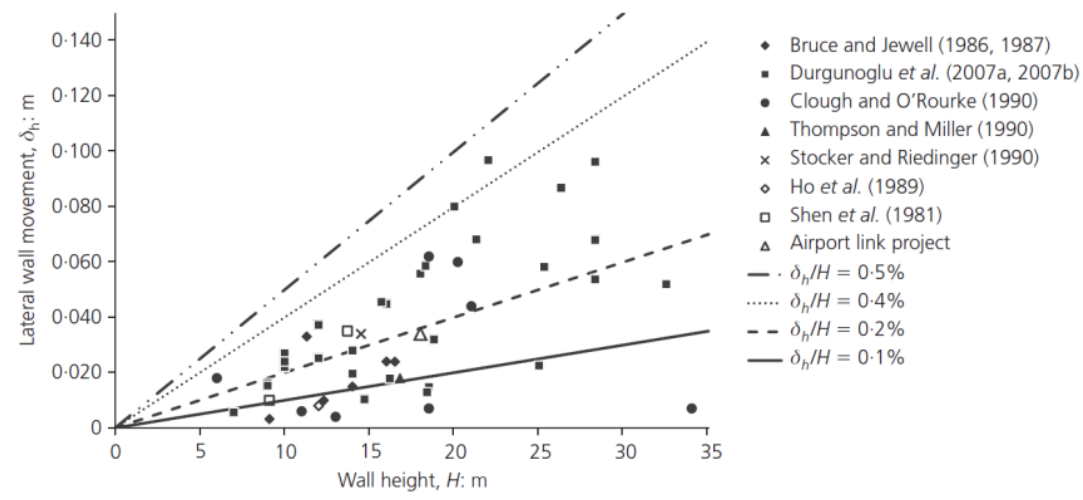

Figure 1. Variation of maximum expected lateral wall deflection against

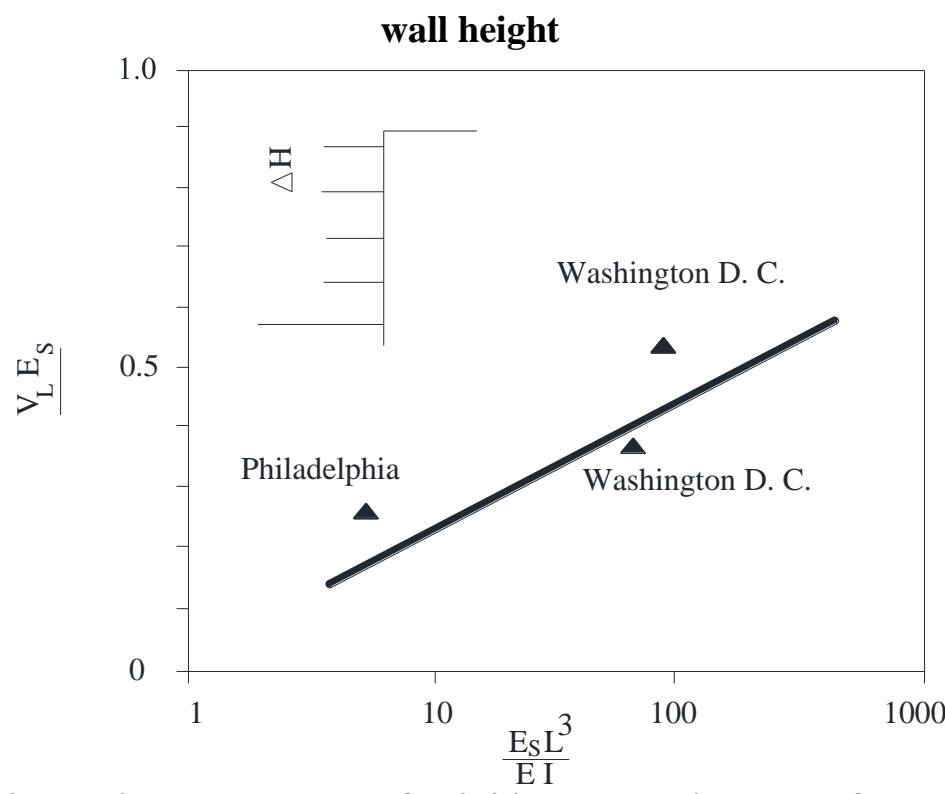

Figure 2. relation between wall flexibility and horizontal deformation of excavation wall

$$
F_{r}=\frac{E_{S} L^{3}}{E_{W} I_{W}}
$$

where, $E_{S}$ is stiffness of soil and $E_{W} I_{W}$ presents the bending stiffness of retaining wall. The settlement profile in surrounding area and mode of wall deformation are also evaluated for types of soil conditions [710]. Some tips to estimate the EIGM are referred in literature [11-13]. 
The importance of EIMG estimation increases when buildings are in close proximity to the excavation area. Prediction of building damage resulted by EIMG is another subject that have recently received much attention by many researchers. To characterize the damage that structure frame has experienced during excavation progress, the term "damage level" is generally used. As a term defining the limiting conditions of expected damage in structure according to EIMG, damage level has been investigated and developed by performing physical scaled model tests [14, and 15], field observations and case studies [16-18], and numerical analyses [19-22].

To evaluate damage levels, observational method could be used as recommended by Burland et al. (1977) [23]. Through this method, damage levels are classified based on observed distortion in the frames of a building and crack width criteria (Table 2).

According to the qualitative classification of observational method which ranges from "Very Slight" (the highest) to "Very Severe" (the lowest), different damage level criteria were developed based on the ground surface settlement and horizontal strain of building frames [24, and 25], differential settlement of building frames, and lateral strain and angular distortion of building frames [18, and 26].

Damage levels of a building could be explained using "deformation parameters" [27, and 28]. As shown in Figure 3, these parameters are controlled by the translation and rotation of the building frames. 
Table 3 presents the classification established by Schuster et al for damage levels in terms of Damage Potential Index (DPI) using the deformation parameters.

Table 2. Classification of Visible Damage to Walls with Particular Reference to Ease of Repair of Plaster and Brickwork or Masonry [23]

\begin{tabular}{|c|c|c|}
\hline $\begin{array}{l}\text { Degree } \\
\text { of } \\
\text { damage }\end{array}$ & Description of typical damage ${ }^{\mathrm{a}}$ (ease of repair is underlined) & $\begin{array}{l}\text { Approximate } \\
\text { crack width }^{\text {b }} \\
(\mathrm{mm})\end{array}$ \\
\hline $\begin{array}{l}\text { Very } \\
\text { Slight }\end{array}$ & $\begin{array}{l}\text { Hairline cracks of than about } 0.1 \mathrm{~mm} \text { are classed as negligible. } \\
\text { Fine cracks which can easily be treated during normal decoration. Perhaps } \\
\text { isolated slight fracture in building. Cracks in external brickwork visible on } \\
\text { close inspection. }\end{array}$ & $<1$ \\
\hline Slight & $\begin{array}{l}\text { Cracks easily filled. Redecoration probably required. Several slight } \\
\text { fractures showing inside of building. Cracks are visible externally and } \\
\text { some repointing may be required externally to ensure weather tightness. } \\
\text { Doors and windows may stick slightly. }\end{array}$ & $1-5$ \\
\hline Moderate & $\begin{array}{l}\text { The cracks require some opening up and can be patched by a mason. } \\
\text { Recurrent cracks can be masked by suitable linings. Repointing of } \\
\text { external brickwork and possibly a small amount of brickwork to be } \\
\text { replaced. Doors and windows sticking. Service pipes may fracture. } \\
\text { Weather tightness often impaired. }\end{array}$ & $\begin{array}{l}5-15 \\
\text { or a number of } \\
\text { cracks } \geq 3\end{array}$ \\
\hline Severe & $\begin{array}{l}\text { Extensive repair work involving breaking out and replacing sections of } \\
\text { walls, especially over doors and windows. Windows and door frames } \\
\text { distorted, floor sloping noticeably. Walls leaning or bulging noticeably, } \\
\text { some loss of bearing in beams. Service pipes disrupted. }\end{array}$ & $\begin{array}{l}15-25 \\
\text { but also } \\
\text { depends on } \\
\text { number of } \\
\text { cracks }\end{array}$ \\
\hline $\begin{array}{l}\text { Very } \\
\text { Severe }\end{array}$ & $\begin{array}{l}\text { This requires a major repair job involving partial or complete re building. } \\
\text { Beams lose bearing; walls lean badly and require shoring. Windows } \\
\text { broken with distortion. Danger of instability. }\end{array}$ & $\begin{array}{l}\text { usually }>25 \\
\text { but depends on } \\
\text { number of } \\
\text { cracks }\end{array}$ \\
\hline
\end{tabular}

${ }^{a}$ In assessing the degree of damage account must be taken of its location in the building or structures.

${ }^{b}$ Crack width is only one aspect of damage and should not be used on its own as a direct measure of it.

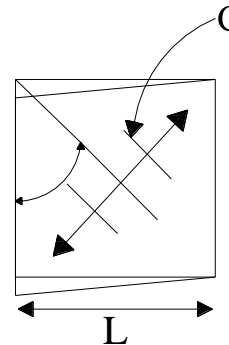

Angular distortion

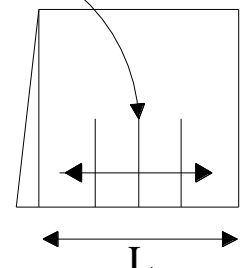

Lateral strain $\varepsilon_{1}=\delta_{1} /$

Figure 3 Deformation parameters that define the distortion of a building frame [18] 
Table 3. Damage levels based on DPI values [31]

\begin{tabular}{ccc}
\hline line & $\begin{array}{c}\text { Level of building } \\
\text { Damage }\end{array}$ & $\begin{array}{c}\text { Damage Potential Index } \\
\text { (DPI) }\end{array}$ \\
\hline 1 & Negligible to Very Slight & $0-15$ \\
2 & Slight & $15-25$ \\
3 & Slight to moderate & $25-35$ \\
4 & moderate & $35-60$ \\
5 & Sever & $60-85$ \\
6 & Very Sever & $>85$ \\
\hline
\end{tabular}

To calculate the DPI values, Eq. 3 is used.

$$
D P I=20 \times 10^{3}\left(\varepsilon_{1} \cos ^{2} \theta_{\text {max }}+\beta \sin \theta_{\text {max }} \cos \theta_{\text {max }}\right)
$$

Where $\beta$ is angular distortion, $\varepsilon_{l}$ is lateral strain (i.e. horizontal strain), and $\theta_{\max }$ is the direction of crack formation measured from the vertical plane. The parameters $\beta$ and $\varepsilon_{l}$ shown in Figure 3 can be obtained using the numerical analysis. In this paper, the DPI approach is used to predict the damage levels in building frames adjacent to the excavation wall to evaluate RNW performance.

The performance of nail in jointed rock medium is rather different from its performance in soil medium because of nail-joints interaction and other geological properties of rock media. A rock mechanics approach to nailing is typically focused on the behavior of discontinuities within the rock mass [2].

The main goal of this study is to investigate the RNW performance. In this regard, wall deflections and damage levels of structure in the EAZ were analyzed by developing 52 FE models, taking into account the interaction between joints and between nails and rock and also considering the rock anisotropy, which are components of the developed FE model specifications. 


\section{Effect of discontinuities on the jointed rock behavior}

In the jointed rock media, the planes of discontinuity control the strength, deformational and hydraulic properties, and general behavior of rock masses. These discontinuities make the rock mass discontinuous and anisotropic, resulting in different strength and deformability in various directions. The term discontinuity, with its probable sedimentary (bedding or lamination planes), diagenetic, or tectonic (joints and faults) origin, refers to any plane of separation or weakness in a rock mass. The stability of the excavations in jointed rock depends on the direction and strength of the discontinuities. The relative orientation of discontinuities may determine whether the excavation wall is stable or not, Figure 4 [29].
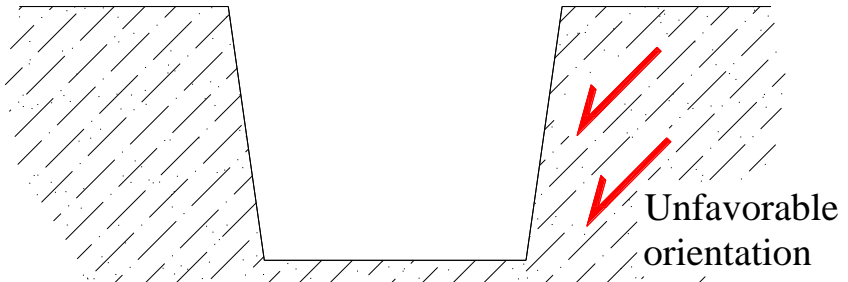

Figure 4. Effect of the relative orientation of discontinuities in relation to excavation wall stability

The effects of joints relative orientation and influence of rock nail in enhancement of excavation stability in excavation wall stability is well described in literature [2]. Figure 5 illustrates the influence of nail in stabilizing the jointed rock. As shown in the Figureure, both "nail angle" and "joint inclination" parameters might affect the stability mechanism of RNW. 


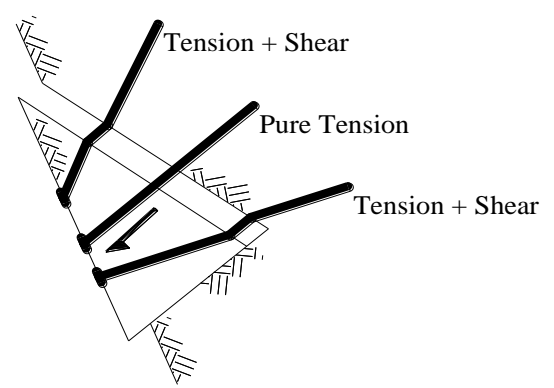

Dilating Discontinuity

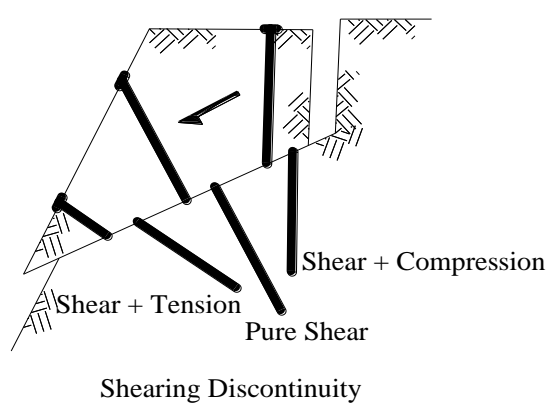

Figure 5. Reinforcement behavior at discontinuity [2, and 30]

Discontinuity in rocks results in different strength and deformability properties in various directions of jointed rock, leading to different response under different load conditions. This so-called "anisotropy" response in jointed rock is considered in the developed FE model by defining of the joints directions and using the jointed rock constitutive model.

\section{Numerical modeling}

The present research seeks to provide a better understanding of RNW performance in jointed rock. In this regard, 2D FE models of nail supported excavation have been developed. Fifteen-node triangle 
plain strain elements were used to model the jointed rock; beam elements were used to model structure frames and rock nails. In order to take into account the interaction between joints, nail and rock, foundation of structure and rock, interface elements were employed using Mohr-Coulomb failure criterion.

The dimensions of models, the size of elements, and the number of nodes were decided after performing a number of sensitivity analyses. The side faces of the model were restrained by rollers, while its bottom was assumed as fixed. The dimensions of RNW and typical view of FE model are shown in Figurers 6 and 7, respectively, for layer inclination equal to +15 degree. The staged analysis used for modeling the RNW supported excavation is presented in Table 4.

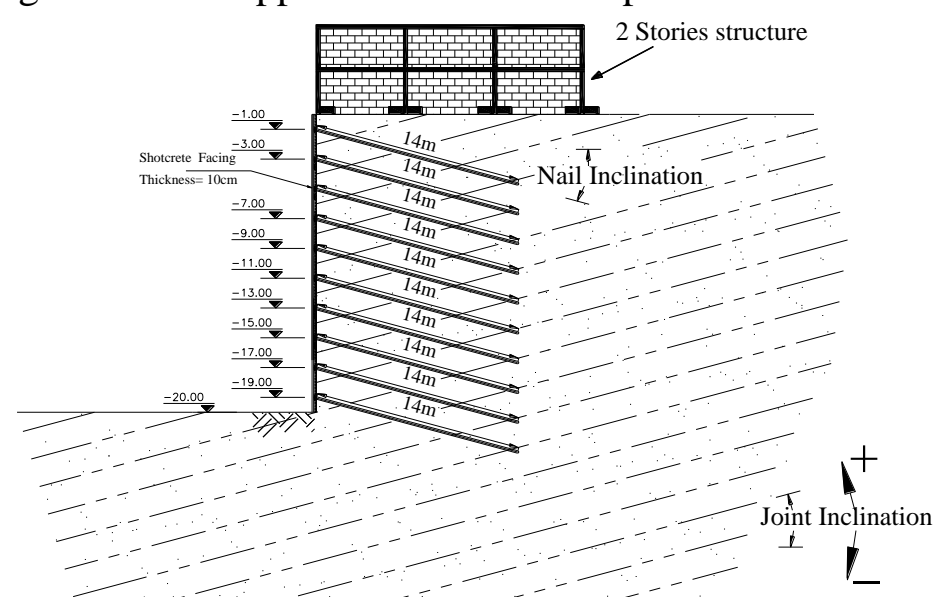

Figure 6 Schematic of FE model and dimensions of RNW Dip 


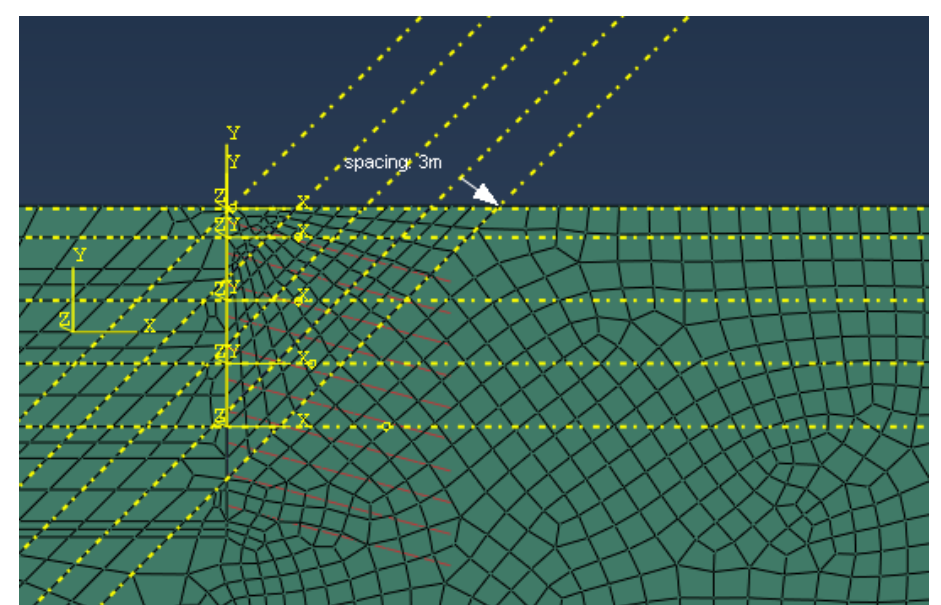

Figure 7 Developed FE model for RNW performance study

Table 4. Phases of FE model staged construction

\begin{tabular}{ll}
\hline $\begin{array}{l}\text { Phase } \\
\text { Number }\end{array}$ & Descriptions \\
\hline 2 & $\begin{array}{l}\text { Assigning the Jointed rock material to the continuum medium } \\
\text { Applying the in situ stress state }\end{array}$ \\
3 & $\begin{array}{l}\text { Activate all interactions between joints } \\
\text { Assign the structure load and stiffness to the model }\end{array}$ \\
5 & $\begin{array}{l}\text { Reset displacement to zero } \\
\text { Deactivate the first 2-meters layer of rock elements and activate the } \\
6\end{array}$ \\
$\begin{array}{l}\text { corresponding nail and shotcrete } \\
\text { Repeat the phase } 6 \text { for other layers up to the excavation bed }\end{array}$ \\
\hline
\end{tabular}

\section{Model verifications}

Recently, a deep excavation project was studied by performing geotechnical and geological investigations, nail wall design, supervising, instrumenting, and monitoring in Tehran, Iran (in Zaferaniyeh). The instrumenting results of this project were used to verify the FE model.

For this purpose excavation wall deflection which predicted using the FE model were compared and verified with the results extracted from the excavation wall monitoring (field results) for two sections of excavation wall. The verification result is shown in Figure 8. 
As shown in Figure 8, the results of present numerical are in good agreement with the measurements. The observed slight tolerance, which is attributed to the variability of rock properties and monitoring errors, is within the reasonable range. The model verifications results demonstrate that the FE prediction in all sections captured the wall deflection appropriately as compared to the monitoring data. Therefore, it can be stated that the present FE model can be confidently used for further studies. In the following sections, a numerical parametric study on the verified FE model is presented and the performance of RNW is analyzed.

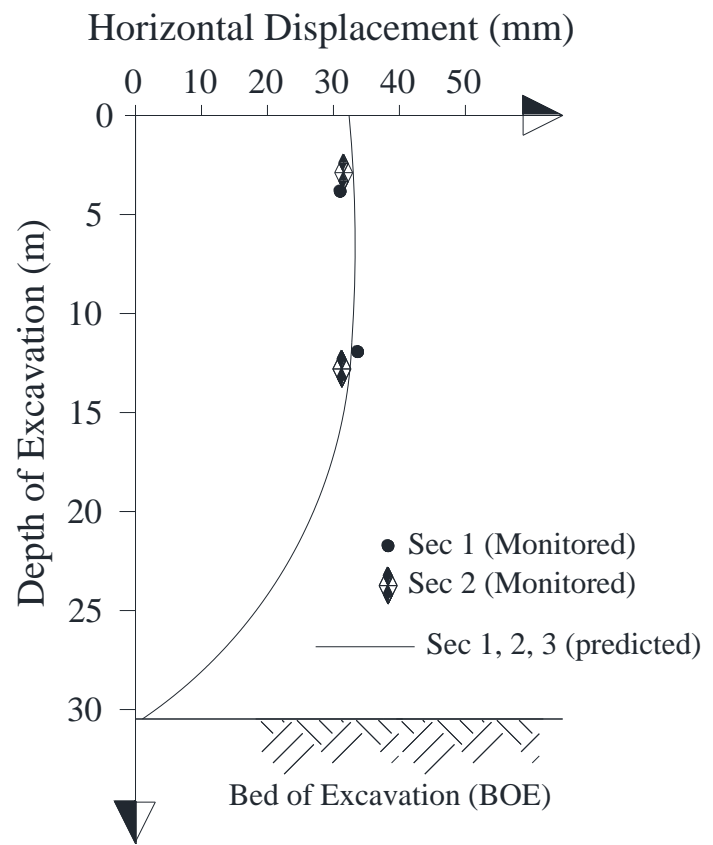

Figure 8. Comparison between results of FE model and monitoring data Numerical results and discussion 
The developed and validated model was used to evaluate the deformation parameters of rock nail supported wall to assess the performance of RNW in plastic and anisotropic half-space.

As mentioned in introduction section, the majority of resent studies are performed on soil nail wall performance and have paid less attention to the performance of rock nail wall (RNW), despite the existing differences between nails response in soil and rock (spatially in jointed or weathered rock). Numerical studies on soil nail wall indicated that several factors including the nails inclination, nails length, and nails spacing affect performance of the soil nail wall. In the present work an attempt was made to examine the effects of these well-known parameters as well as some other important parameters (given in Table 5) on RNW performance. So, the basic constitutive model parameters of jointed rock medium were determined and presented in Table 6.

Table 5. Range of variables in parametric study

\begin{tabular}{|c|c|c|c|}
\hline $\begin{array}{l}\text { Geometric } \\
\text { parameters }\end{array}$ & Ranges & Material parameters & Ranges \\
\hline $\begin{array}{l}\text { Layer inclination } \\
\text { Nail inclination } \\
\text { Joints spacing }\end{array}$ & $\begin{array}{l}-45 \text { to } 45 \\
0 \text { to } 30 \\
0.5 \mathrm{~m} \text { to } 2.5 \mathrm{~m}\end{array}$ & Anisotropy $\left(\mathrm{E}_{1} / \mathrm{E}_{2}\right)^{\mathrm{a}}$ & 1 and 3 \\
\hline \multicolumn{4}{|c|}{$\begin{array}{l}\text { E1: elastic modulus along the joints direction, E2: elastic modulus perpendicular to the } \\
\text { joints direction }\end{array}$} \\
\hline \multicolumn{4}{|c|}{$\begin{array}{l}\text { To investigate the rock nail performance, various deformation } \\
\text { parameters including cantilever deflection (CD), lateral bulging (LB), } \\
\text { and maximum settlement (MS) are defined and used in parametric } \\
\text { study (Figure 9). Typical result of FE model is shown in Figure } 10 \text {. }\end{array}$} \\
\hline
\end{tabular}


Table 6. Material properties used in numerical analysis

\begin{tabular}{|c|c|c|c|c|c|}
\hline \multirow[b]{2}{*}{ General and elastic parameter } & \multicolumn{3}{|c|}{ Jointed rock parameters } & \multirow[b]{2}{*}{ ter } & \multirow[b]{3}{*}{$\mathrm{KN} / \mathrm{m}^{2}$} \\
\hline & & & Plastic param & & \\
\hline \multirow{2}{*}{$\begin{array}{l}\text { Unit weight of rock medium } \\
\text { Young's modulus for rock as a } \\
\text { continuum }\end{array}$} & 30 & $\overline{\mathrm{KN}} / \mathrm{m}^{3}$ & Cohesion & 200 & \\
\hline & $3 \mathrm{E} 5$ & $\mathrm{KN} / \mathrm{m}^{2}$ & Friction angle & 35 & degree \\
\hline Poisson's ratio & 0.25 & - & $\begin{array}{l}\text { Dilatancy } \\
\text { angle }\end{array}$ & 5 & degree \\
\hline \multirow[t]{3}{*}{ Shear modulus ratio } & $1.2 \mathrm{e} 5$ & $\mathrm{KN} / \mathrm{m}^{2}$ & $\begin{array}{l}\text { Tensile } \\
\text { strength }\end{array}$ & 0 & $\mathrm{KN} / \mathrm{m}^{2}$ \\
\hline & & $\mathrm{KN} / \mathrm{m}^{2}$ & Dip angle & $\begin{array}{l}\text { Dependent to layer } \\
\text { Inc. }\end{array}$ & degree \\
\hline & & - & Dip direction & $\begin{array}{l}\text { Dependent to layer } \\
\text { Inc. }\end{array}$ & degree \\
\hline
\end{tabular}

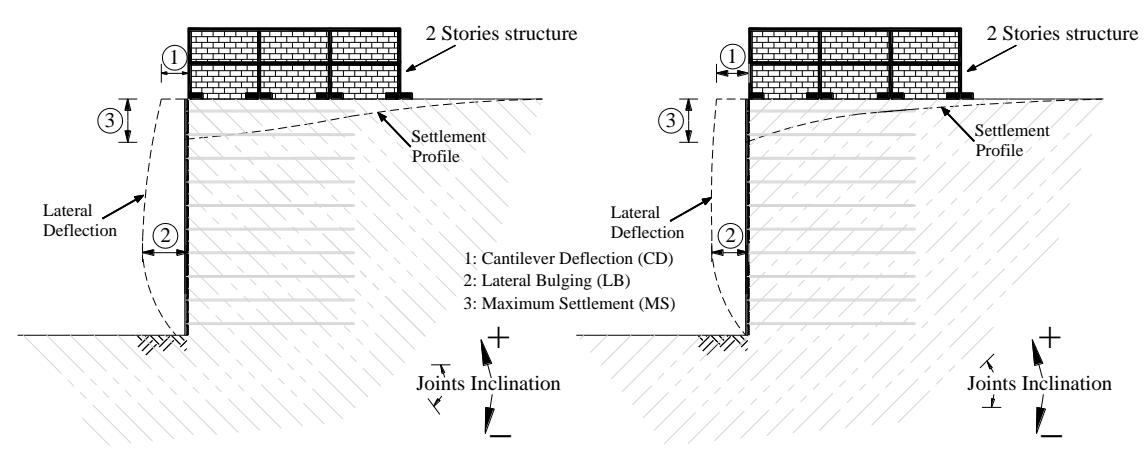

Figure 9. Definition of wall deformation parameters used in the parametric study presented in this study

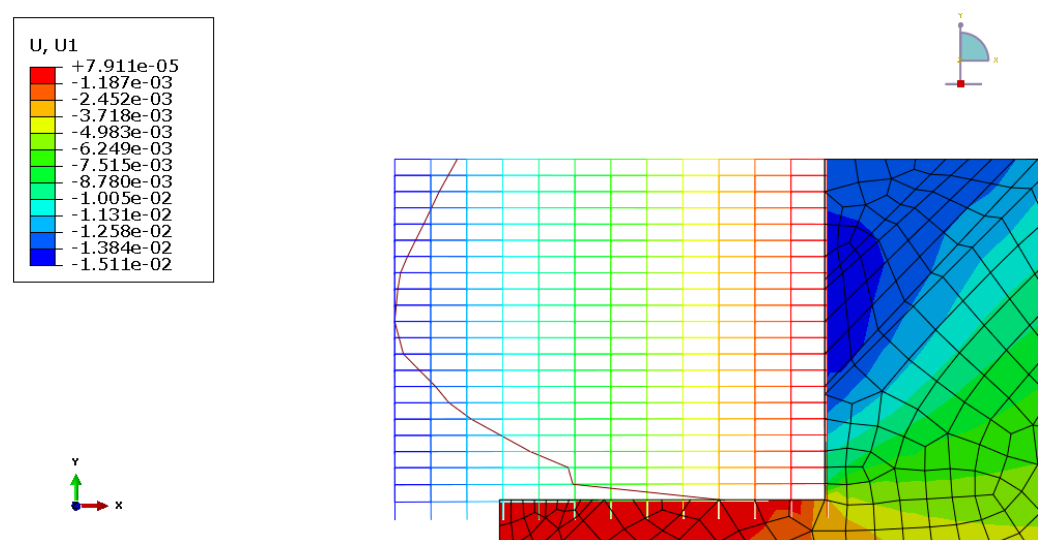

Figure 10. Typical result of FE model (Horizontal Displacement) 


\section{Effect of joints inclination on deflection mode of RNW}

Deflection mode of excavation wall influences the damage level in the structures in its vicinity. In cantilever deflection causes horizontal strain, on the other hand, lateral bulging, and settlement leading to the angular distortion in adjacent structures [30].

In jointed rock medium, joints direction dominantly affects the mode of wall deflection. The influence of joints direction on the CD and LB are shown in Figures. 11, 12 and 13 for nail angles $0^{\circ}, 1^{\circ}$, and $30^{\circ}$, respectively. Here, the jointed rock is considered as isotropic $\left(E_{1} / E_{2}=1\right)$ and joint space (JS) is assumed to be equal to $2 \mathrm{~m}$. The vertical axis indicates the value of displacement in millimeter. The direction of negative and positive joints inclination is shown in the tagged Figureures in both sides of Figure 11.

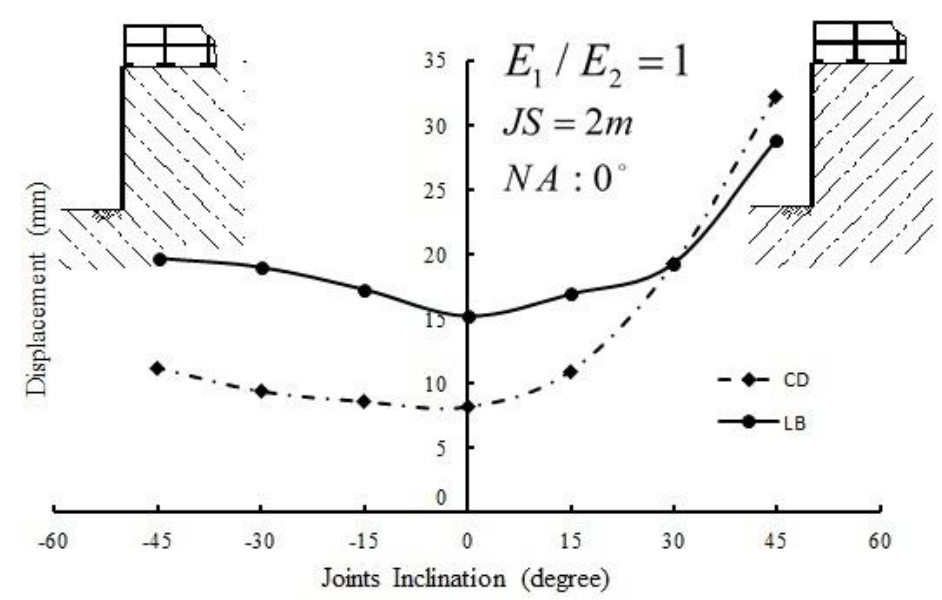

Figure 11. Effect of joints dip on cantilever displacement and lateral bulging, nail angle $0^{\circ}$

As shown in these Figurers, both $\mathrm{CD}$ and $\mathrm{LB}$ values have infinitesimal changes in joint inclination range of -45 to 0 ; however, 
the values increase significantly by the rise of joints inclination from 0 to 45 . This trend is similar for all examined nail angles. An important result observed from these Figureures is the variability of dominant deflection mode by variation of joints inclination. Based on these results, by an increase in joints inclination value, the RNW has a tendency to behave as a cantilever wall.

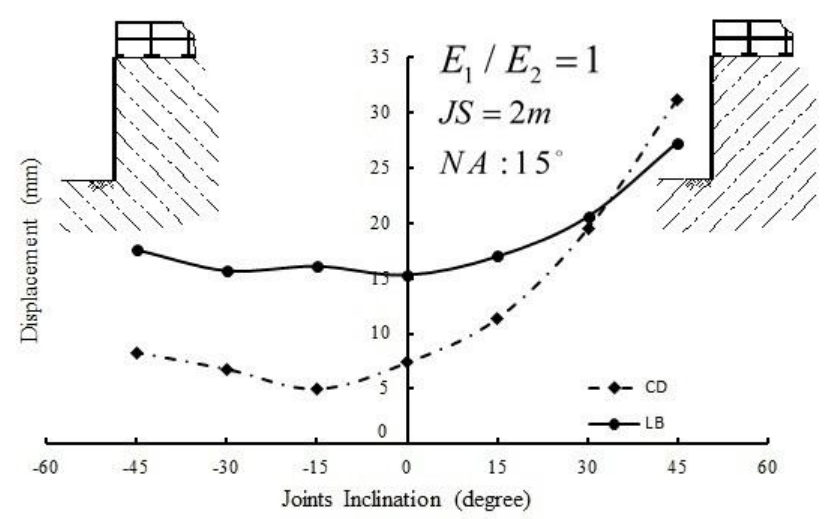

Figure 12. Effect of joints dip on cantilever displacement and lateral bulging, nail angle $15^{\circ}$

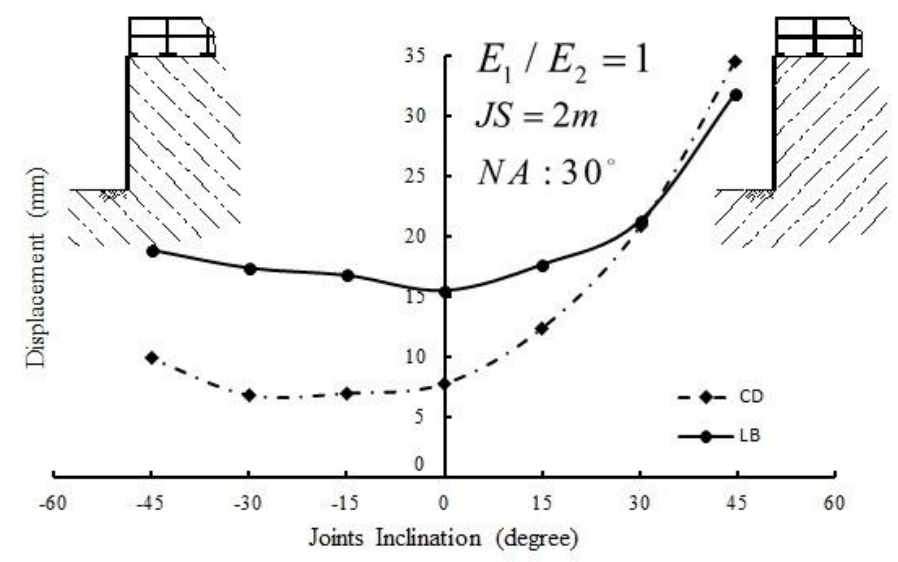

Figure 13. Effect of joints dip on cantilever displacement and lateral bulging, nail angle $30^{\circ}$ 


\section{Effect of joints dip on deformation parameters of RNW}

In previous subsection, the effect of joints dip on wall deflection mode was investigated by assuming jointed rock as an isotropic medium. In order to obtain a more real insight into nail wall response in jointed rock medium, the anisotropy equal to 3 was considered for rock medium. By taking into account the anisotropy effect, the influence of joints inclination on CD and LB for different nail angles is shown in Figureures. 14 and 15, respectively.

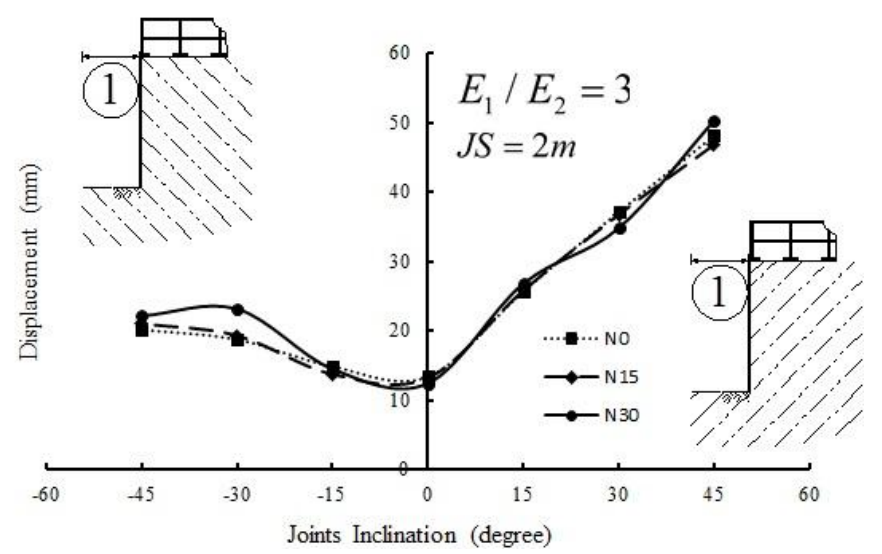

Figure 14. Effect of joints dip on cantilever deflection where anisotropy equals to 3

When the joints dip is almost zero, the least value for wall deformation occurred. In other words, the value of $\mathrm{CD}$ and $\mathrm{LB}$ of nail wall in jointed rock with horizontal joints is less than the corresponding values in jointed rock with oblique joints. This trend can be attributed to the joints slippage and anisotropic properties of jointed rock. It should be noted that based on the defined anisotropy properties (Table 5), the elastic modulus perpendicular to the joints direction is less than the elastic modulus along the joints direction. So, 
for negative values of joints dip, the deformation of nail wall in jointed rock will be more than the corresponding values in jointed rock with horizontal joints. It can also be observed that the variation of $\mathrm{LB}$ is less than the variation of $\mathrm{CD}$ in the range of investigated parameters. The trend of curves is the same for all of examined nail angles. Similar to the isotropic situation, an increase in joints inclination value, the RNW has a tendency to behave as a cantilever wall.

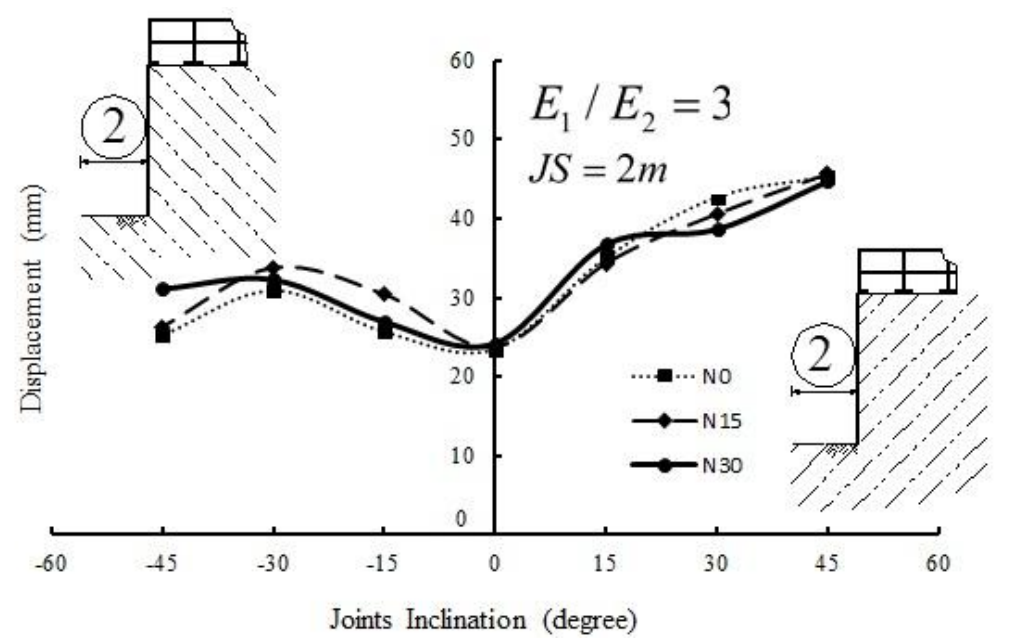

Figure 15 Effect of joints dip on lateral bulging where anisotropy equals to 3

The effect of joints dip on maximum settlement is examined and shown in Figure 16. The vertical axis shows the value of maximum settlement in millimeter.

As indicated in Figure 15, the maximum settlement for positive values of joints dip can increase up to twice as compared to the zero and negative values of joints inclination. The mentioned parameter had negligible variation for negative values of joints dip. 


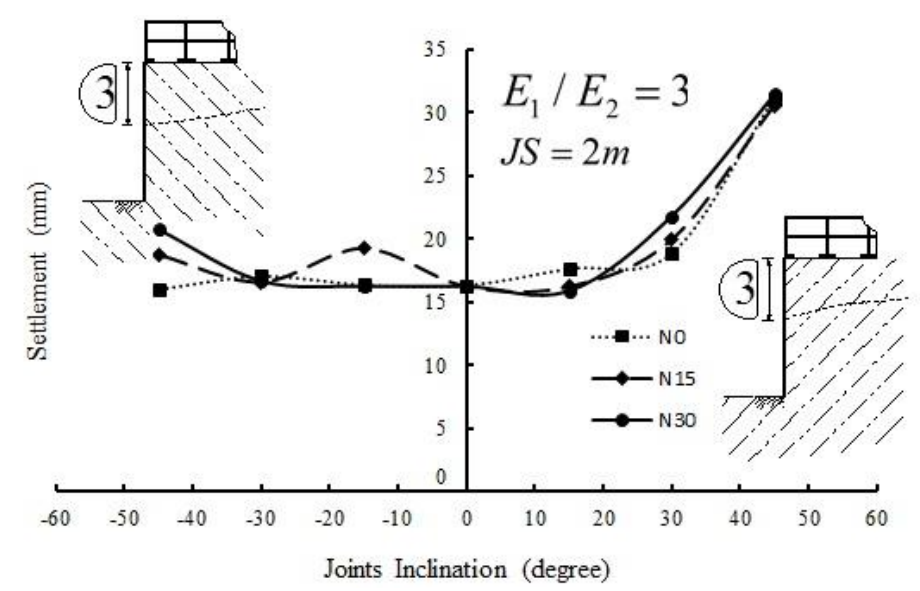

Figure 16 Effect of joints dip on maximum settlement where anisotropy equals to 3

If the generated settlement under the structure is uniform, the structure encounters less damage in comparison with the structure with non-uniform settlement. So, effect of joints inclination on settlement ratio was investigated. Settlement ratio was defined as the ratio between maximum and minimum settlement under adjacent structure. Figure 17 shows the effect of joints dip on settlement ratio where anisotropy is 3 .

The results show that settlement ratio increases by the increase in joints inclination for its positive values. In left side of the Figureure, there exists a peak in curves at joints inclination $-15^{\circ}$. Figure16 also demonstrates that the settlement is more uniform for greater nail angles.

\section{Effect of joints spacing on deformation parameters of RNW}

Spacing is defined as the average perpendicular distance between discontinuity planes in the same set. It controls the size of blocks of 
intact rock and affects the overall behavior of a rock mass. With small spacing, the strength of the rock mass is considerably reduced, and in extreme cases a granular-like behavior is observed in non-cohesive materials [31].

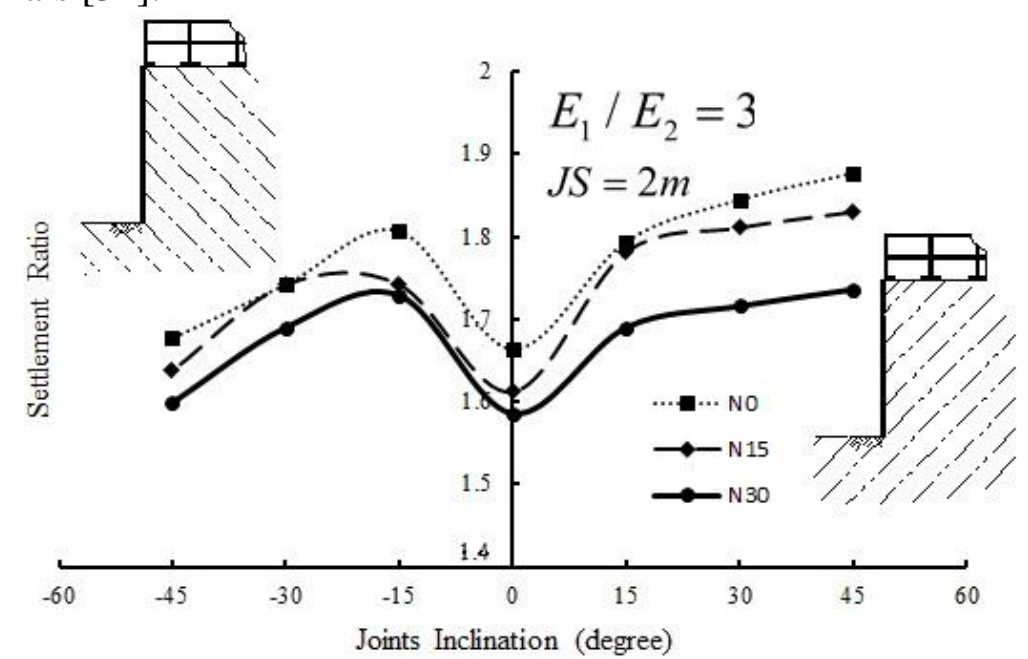

Figure 17 Effect of joints dip on settlement ratio where anisotropy equals to 3

To evaluate the effects of joints spacing in the study of excavation wall performance or stability, the relative dimensions of the both the rock mass structure and the separation between discontinuities to the excavation depth should be considered. The RNW performance is studied in the jointed rock medium with the joints spacing $0.5,1,1.5$, 2 , and $2.5 \mathrm{~m}$. The mentioned values are corresponding to $0.025,0.05$, $0.075,0.1$, and 0.125 of the excavation depth, respectively. To investigate the effects of spacing on wall performance, the variations of cantilever displacement and maximum settlement respective to joints spacing were plotted in Figureures. 18 and 19. 


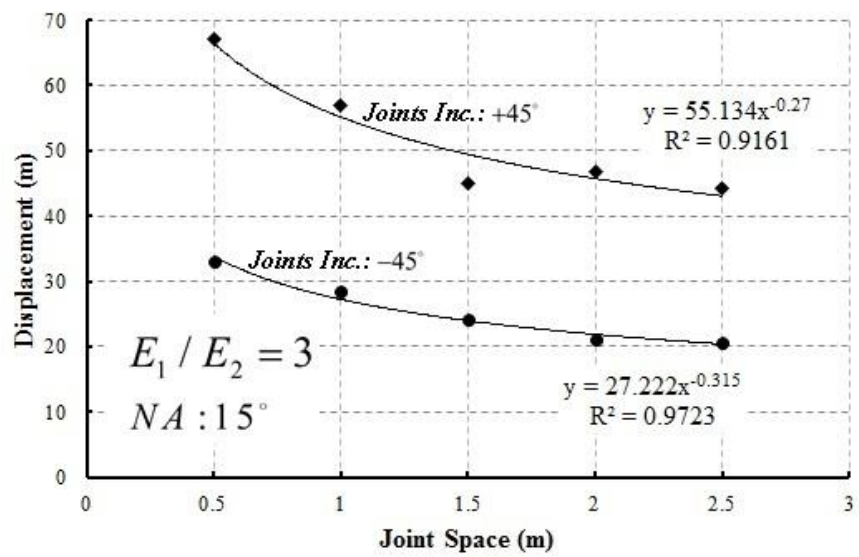

Figure 18. Effect of joints dip on CD

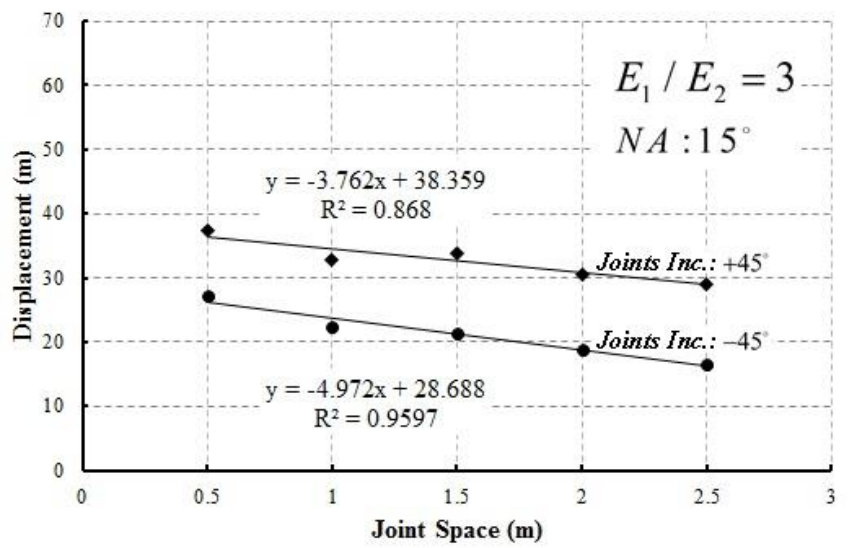

Figure 19 Effect of joints dip on MS

The power and linear functions are defined to characterize the variation of cantilever displacement and maximum settlement, respectively. Here, the excavation-induced deformation and related damage decreases with the increasing joints spacing.

\section{Effect of joints inclination on damage level of structures in EAZ}

The effects of joints inclination on damage level was studied regarding the results of FE models. To estimate the damage level in 
frames of a structure in EAZ, the DPI concept is used [33]. To calculate the DPI, the value of displacements was obtained for the corners of each frame of the structure and then $\varepsilon_{1}$ and $\beta$ values were calculated using equations presented in Figure 3. DPI is computed via Eq. 3 using the values of mentioned two parameters.

The distribution of DPI in frames of a structure in EAZ is presented in Figure 20 for two examined cases. In this Figurer, the horizontal axis presents the position of each frame in the structure and the vertical axis shows the corresponding values of DPI in each frame. The labeled numbers to each point present DPI value associated with the studied frame. It should be mentioned that the adjacent structure was modeled using beam elements in two stories and three frames (each frame, $5 \mathrm{~m}$ in width). Nail bars array and other characteristics of the model were selected according to Figure 10.

As shown in Figure 20, the value of DPI calculated for frames of the structure with joints inclination +45 is more than the corresponding value for joints inclination equal to $-45^{\circ}$, particularly in the first frame. A comparison between DPI values for the frames of first and second floors reveals that maximum damage (maximum DPI) occurred in the middle frame of the first floor.

The maximum DPI (MDPI) in the critical frame of structure is 43 and 34 for excavation in jointed rock with joints inclination equal to +45 and $-45^{\circ}$, respectively. As shown in Figure21, for other values of joints dip, the MDPI is calculated similarly. 


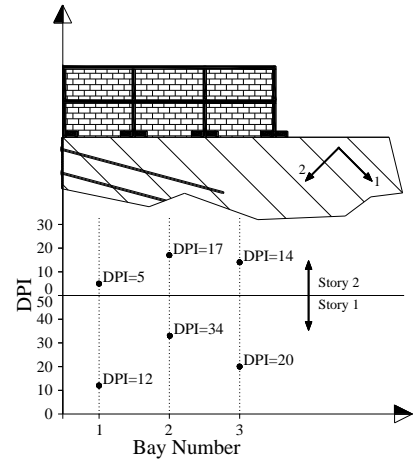

a' Inints inclination' -45

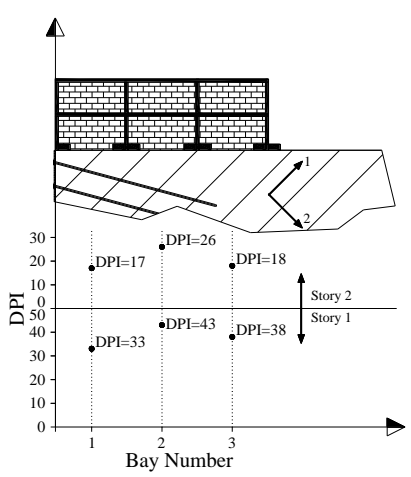

h. Inints inclination +45

Figure 20. Variations of DPI in frames of structure adjacent to the excavation wall under joints dip equal to (a) $-45^{\circ}$; (b) $+45^{\circ}$

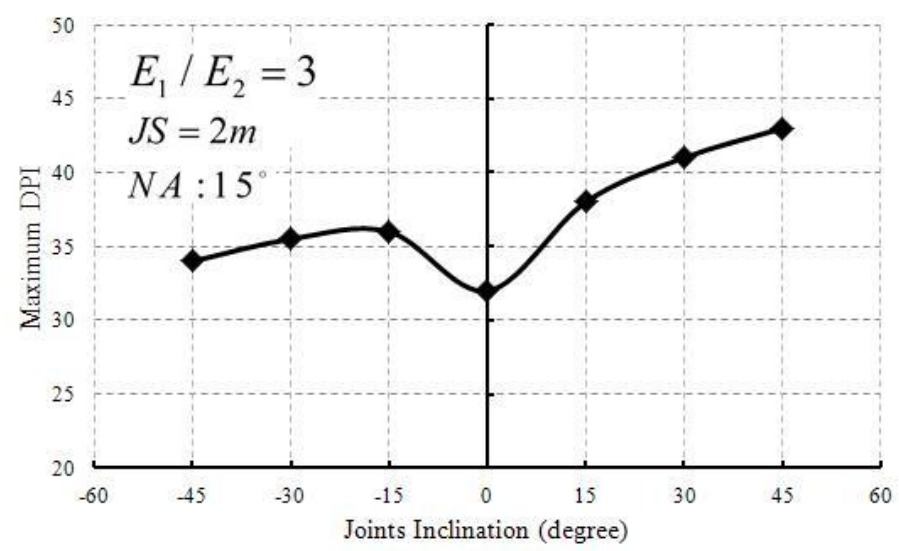

Figure 21. Effect of joints dip on maximum DPI

According to these results, it can be concluded that the minimum damage to the structure in ZAE occurs when the joints inclination is zero. Similar to the variation of settlement ratio, the MDPI curve indicates a peak for the negative values of joints inclinations. The damage level of the structure raises by the increase in positive values of joints inclination.

To obtain a deeper insight of the damage variation with the joints inclination in the range of investigated parameters, the variation of 
MDPI is compared with cantilever deflection, lateral bulging, maximum settlement, and settlement ratio (Figure 22). To provide a qualitative comparison between the results, the vertical axis was scaled for each parameter

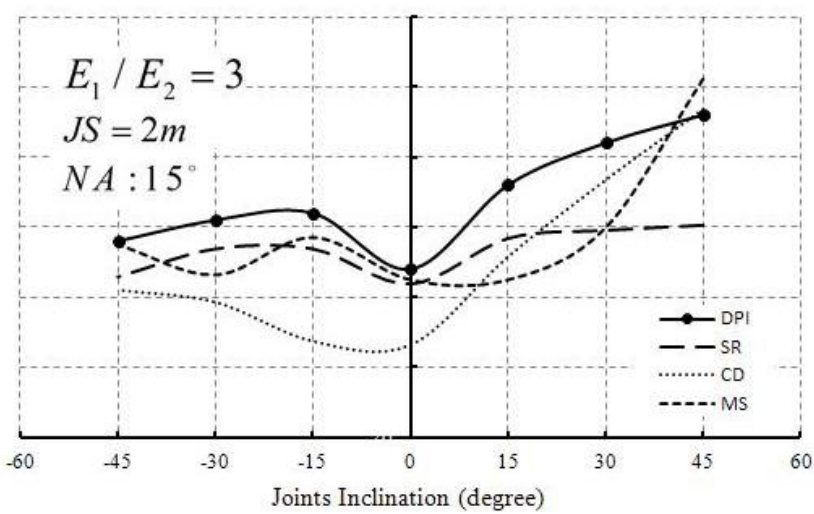

Figure 22. Variations of DPI, Settlement Ratio, Cantilever Displacement, and Maximum Settlement versus joints dip

As shown in the Figureure, the variation of MDPI follows the trend of settlement ratio and cantilever deflection in most parts. The Figureure also indicates that the excavation induced deformation generally has the least value when the joints inclination is zero.

The Figureure shows that for jointed rocks medium with negative joints dip, the deformation and related damage is greater in comparison with jointed rock medium with horizontal joints; despite the fact that stability is higher for jointed rock medium with negative joints inclination. This response can be attributed to the anisotropic specifications of jointed rock medium. 


\section{Summary and conclusion}

The paper presented the results of a comprehensive numerical analysis carried out to investigate the performance of nail wall in jointed rocks medium. Taking into account joint-rock-structure interaction and anisotropic properties of jointed rocks, the deformation parameters of excavation zone supported by RNW and the damage level of structure in EAZ were investigated for different conditions of joints dip and spacing. The dependency of excavation-induced ground movements and related damage is also mentioned in this work. The most important findings of this study can be summarized as follows:

1. The dominant deflection mode of RNW was evaluated for a range of joints dip values. Results showed that RNW has a tendency to behave as a cantilever wall by increasing the joints dip value.

2. The power and linear functions can be defined to characterize the variation of cantilever displacement and maximum settlement versus joints spacing variations.

3. The damage level of structure in EAZ and the value of excavation-induced deformation parameters are highly controlled by the relative orientation between excavation wall and joints dip. The variation of these parameters showed that the values of deformation parameters and level of damage are greater for positive values of joints dip in comparison with negative values.

4. For jointed rock medium with negative joints dip, the deformation and related damage level is higher as compared to the jointed rock medium with horizontal joints; despite the fact that stability is higher for jointed rock medium with negative joints dip. This 
response can be attributed to the anisotropic specifications of jointed rock medium. Also, the quantified analogy between the results was presented in this paper.

\section{References}

1. Lazarte C.A., Victor Elias P.E., Espinoza R.D., Sabatini P.J., "Soil Nail Walls" Report FHWA0-IF-03-017, Washington, D.C. 20590 (2003).

2. Gilbert R., Nelson P., Young C., Moses B., Al-Jalil Y., "Rock nail design guidelines for roadway cuts in central Texas", Report FHWA/TxDOT96/1407-1F, Texas Department of Transportation Research and Technology, 358 (1995).

3. Ghahreman B., "Analysis of ground and building response around deep excavation in sand", Ph. D. Thesis, Department of civil engineering, university of Illinois (2004).

4. Peck R.B., "Deep excavation and tunneling in soft ground", Proceedings of the seventh international conference on soil mechanics and foundation engineering, Mexico City, state of the art, 225-290 (1969).

5. O'Rourke T.D., "A study of two braced excavations in sand and interbedded stiff clay", Ph. D. thesis, department of civil engineering, university of Illinois, (1975).

6. Cording E., "Use of empirical data for braced excavations and tunnels in soil", Lecture series, Chicago ASCE (1984).

7. Terzaghi K., Peck R.B., Mesri G., "Soil mechanics in engineering practice", 3rd Edition, John Wiley and Sons, New York (1996).

8. Muller C.G., Long J.H., Weatherby D.E., Cording E.J., Powers W.F., Briaund J.L., "Summary report of research on permanent ground anchor walls", Vol. 3 (1998). 
9. Finno R.J., Roboski J.F., "Three-dimensional response of a tied-back excavation throughclay", J. Geotechnical and Geoen. Engineering, Vol. 131, No. 3, (2005) 273-282.

10. Kung G.T.C., Juang C.H., Hsiao E.C.L., Hashash Y.M.A., "A simplified model for wall deflection and ground surface settlement caused by braced excavation in clays", J. Geotechnical and Geoenvironmental Engineering, ASCE, Vol. 133, No. 6 (2007) 731-747.

11. Calvello M., Finno R.J., "Selecting parameters to optimize in model calibration by inverse analysis", Computers and Geotechnics, 31 (5) (2004) 411-425.

12. Finno R.J., Calvello M., "Supported excavations: observational method and inverse modeling", Journal of Geotechnical Geoen. Engineering, ASCE, 131(7), (2005) 826-836.

13. Kung G.T.C., Hsiao E.C.L., Juang C.H., "Evaluation of a simplified small strain soil model for estimation of excavation-induced movements", Canadian Geotechnical Journal, Vol. 44, No. 6, (2007) 726-736.

14. Laefer D.F., "Prediction and assessment of ground movement and building damage induced by adjacent excavation", $\mathrm{Ph}$. D. Thesis, Department of civil and environmental engineering, university of Illinois, (2001).

15. Sawwaf M.E., Nazir A.K., "The effect of deep excavation-induced lateral soil movements on the behavior of strip footing supported on reinforced sand", J. Advanced Research (2011).

16. Son M., Cording E.J., "Estimation of Building Damage Due to Excavation-Induced Ground Movements", J. Geotechnical Geoen. Engineering, Vol. 131, No. 2 (2005)162-177. 
17. Bryson L.S., Kotheimer M.J., "Cracking in Walls of a Building Adjacent to a Deep Excavation", J. performance of construction facilities, Vol. 25, No. 6 (2011) 491-503.

18. Halim D., Wong K.S., "Prediction of Frame Structure Damage due to Deep Excavation", J. Geotechnical Geoenvironmental Engineering (2014).

19. Yoo C., Lee D., "Deep excavation-induced ground surface movement characteristics-A numerical investigation", J. Computers and Geotechnics, 35, (2007) 231-252.

20. Son M., Cording E.J., "Evaluation of Building Stiffness for Building Response Analysis to Excavation-Induced Ground Movements", J. Geotechnical Geoenvironmental Engineering, Vol. 133, No. 8, (2007) 995-1002.

21. Son M., Cording E. J., "Responses of Buildings with Different Structural Types to Excavation-Induced Ground Settlements", J. Geotechnical Geoenvironmental Engineering, Vol. 137, No. 4 (2011) 323-333.

22. Bryson L.S., Zapata-Medina D.J., "Method for Estimating System Stiffness for Excavation Support Walls", J. Geotechnical Geoenvironmental Engineering, (2012).

23. Burland J., Broms B., DeMello V., "Behavior of foundations and structures: state-of-the-art report", Proceedings of the 9th international conference on soil mechanics and foundation engineering, Japanese geotechnical society, Tokyo, Japan (1977) 495-546.

24. Burland J.B., "Assessment of risk of damage to building due to tunneling and excavation", Pro of the 1th international conference on earthquake geotechnical engineering, IS-Tokyo (1995). 
25. Boscardin M., Cording E., "Building response to excavation induced settlement", J. Geotechnical Engineering Division, ASCE, Vol. 115, (1989) 1-21.

26. Son M., "The response of buildings to excavation-induced ground movements", Ph. D. thesis, Univ. of Illinois at Urbana-Champaign, Urbana, Ill (2003).

27. Boscardin M.D., "Building response to excavation induced movements", Ph. D. Thesis, Department of civil engineering, university of Illinois, (1980).

28. Burland J.B., "Assessment of risk of damage to building due to tunneling and excavation", Pro of the 1th international conference on earthquake geotechnical engineering, IS-Tokyo (1995).

29. Gonzales de Vallejo. L., Ferrer M., "Geological Engineering", published by: CRC press/Balkema, Taylor \&Francis Group, London, ISBN: 978-0415-41352-7 (2011) 678.

30. Juang C., Schuster M., Yu Ou C., Phoon K., "Fully Probabilistic Framework for Evaluating Excavation-Induced Damage Potential of Adjacent Buildings", J. Geotechnical and Geoenvironmental Engineering, Vol. 137, No. 2 (2011) 130-139.

31. Schuster M., "Framework for the fully probabilistic analysis of excavation-induced serviceability damage to buildings in soft clays", $\mathrm{Ph}$. D. Thesis, Univ. of Illinois at Urbana-Champaign, Urbana, Ill, (2008).

31. Schuster M., Kung G., Juang C., Hashash M., "Simplified Model for Evaluating Damage Potential of Buildings Adjacent to a Braced Excavation", J. Geotechnical and Geoenvironmental Engineering, Vol. 135, No. 12 (2009) 1823-1835. 